\title{
Qualitative Analysis of Student Perceptions of Bachelor of Science-to-Doctor of Philosophy in Nursing Programs
}

Neil E. Peterson

Brigham Young University - Provo, neil-peterson@byu.edu

Karen O. Moss

Gwyneth R. Milbrath

Jane R. von Gaudecker

Eunhee Park

Eellone this and fadditionah workshat: https://scholarsarchive.byu.edu/facpub

Part of the Nursing Commons

\section{Original Publication Citation}

Peterson, N. E., Moss, K. O., Milbrath, G. R., von Gaudecker, J.,R., Park, E., \& Chung, M. (2015).

Qualitative analysis of student perceptions of bachelor of science-to-doctor of philosophy in nursing programs. Journal of Nursing Education, 54(10), 542-549. doi:10.3928/

01484834-20150916-01

\section{BYU ScholarsArchive Citation}

Peterson, Neil E.; Moss, Karen O.; Milbrath, Gwyneth R.; von Gaudecker, Jane R.; Park, Eunhee; and Chung, Mihee, "Qualitative Analysis of Student Perceptions of Bachelor of Science-to-Doctor of Philosophy in Nursing Programs" (2015). Faculty Publications. 1792.

https://scholarsarchive.byu.edu/facpub/1792

This Peer-Reviewed Article is brought to you for free and open access by BYU ScholarsArchive. It has been accepted for inclusion in Faculty Publications by an authorized administrator of BYU ScholarsArchive. For more information, please contact ellen_amatangelo@byu.edu. 


\section{Authors}

Neil E. Peterson, Karen O. Moss, Gwyneth R. Milbrath, Jane R. von Gaudecker, Eunhee Park, and Mihee Chung 


\begin{abstract}
Background: To address the shortage of $\mathrm{PhD}$-prepared nursing faculty, universities in the United States of America offer direct entry BSN-to-PhD nursing programs. Little research has been done to explore students’ perceptions of these programs and formally evaluate the successes and opportunities for growth of this academic track. Methods: Focusing on the perceptions and experiential reflection of BSN-to-PhD education, a survey with open-ended questions was distributed among voluntary participants who are current BSN-to-PhD students or recent graduates ( $<5$ years) from various universities in the country. Textual data were analyzed using a qualitative descriptive approach with thematic analysis. Results: This article elaborates on opportunities, challenges, and suggestions related to this educational route as recognized by 21 participants from seven universities. Conclusion: The findings of the study may facilitate discussion among nurse educators to revise programs to be congruent with the needs of current students while paving the way for future scholars.
\end{abstract}




\section{A Qualitative Analysis of Student Perceptions of BSN-to-PhD Nursing Programs}

The development of future nurse faculty persists as a pressing need for the profession (Scherzer, Stotts, \& Fontaine, 2010). In nursing, those interested in advanced education usually work for several years before starting a master’s degree and work several more years after completing a master's degree before eventually starting doctoral studies later in his/her career (Cathro, 2011; McBride, 1999). This results in nursing faculty, researchers, and leaders who are older, reducing career time dedicated to teaching and research prior to retirement. This constitutes the singular most consequential reason for the nursing shortage and ultimately the reduced nursing research and education workforce (American Association of Colleges of Nursing [AACN], 2014).

Addressing the shortage of $\mathrm{PhD}$-prepared nursing faculty is a priority for the profession, as the shortage is predicted to intensify in just a few short years. Results from a recent survey by the AACN indicated that there were almost 1500 faculty vacancies or additionally needed positions across the United States, of which approximately 1265 are doctoral-level positions (AACN, 2014). The schools in the survey indicated that the number one reason for being unable to fill vacancies was a lack of doctorally-prepared applicants (AACN, 2014). Although PhDprepared nurses taking positions outside of the academic arena may be contributing to the limited pool of qualified applicants, likely the source of the problem lies in insufficient numbers of graduating nurse scientists. Furthermore, the average age of doctorally-prepared professors, associate professors, and assistant professors was 61, 58, and 52 years respectively (AACN, 2014). With the average age of nursing faculty retirement at just over 62 years (Berlin \& Sechrist, 2002), by extrapolation this means that approximately $50 \%$ of all current nursing faculty could be retired 10 years from now. 
Although nurse faculty shortage is an important reason necessitating additional doctorally-prepared nurses, another key reason that cannot be overlooked is the need to address the ever-changing landscape of nursing and healthcare. Simply put, the way nursing research has been done in the past is not how it will be in the future. Most governmental and large organization calls for proposals now emphasize multidisciplinary teams, with interprofessional collaboration, data sharing, and stressing interventions and outcomes. The importance of having input from the rising generation of nurse researchers is likely one reason organizations like the National Institutes of Health make a special effort to encourage new researchers to apply for funding. These funding agencies value the contribution of a younger generation of nursing scholars.

One solution to preparing younger, doctorally-prepared nurses is by taking advantage of the many Bachelor of Science in Nursing [BSN] to PhD programs available in the United States. These BSN-to-PhD programs follow a more tradition model of $\mathrm{PhD}$ study found in other science fields — students are admitted to the program after completion of a bachelor's education, and receive master's- and doctoral-level coursework en route to a PhD.

Unlike registered nurse or nurse practitioner credentialed programs, there is a wide variety in curriculum across programs, which are less regulated than pre-licensure programs. Of the 128 nursing PhD programs in the United States (AACN, 2013a), 81 offer a fast-track option for baccalaureate-prepared nurses to obtain a PhD (AACN, 2013b). Some programs award a master's degree during the doctoral curriculum, which, depending on the program, can be further specialized as it applies to the doctoral studies and future program of research.

Despite the abundance of these programs, little research has been done to formally evaluate the successes and opportunities for growth of this academic track. Although a few 
expert opinion papers and editorials by faculty and researchers have addressed BSN-to-PhD programs, few studies explore the perceptions of these programs by the students themselves (Nehls \& Rice, 2014). If preparing future nurse researchers who will stay in the field is a priority for the nursing profession, investigating how these programs succeed and could improve is essential. The purpose of this study was to explore perceptions and experiences of current and former BSN-to-PhD students by surveying a sample of students from these doctoral programs in various geographic locations throughout the United States and identify successes and challenges with this educational route.

\section{Methods}

\section{Design}

Descriptive qualitative research methods using an online survey were used to explore the nurses' perception and experiences of BSN-to-PhD education and to identify opportunities and challenges with this educational route. Textual analysis was guided by a qualitative descriptive approach. Thematic analysis was based on some a priori assumptions that both successes and challenges would emerge; however, a cycle of both deductive and inductive coding was used to guide the exploration of the participant responses. The research team consisted of currently enrolled BSN-to-PhD nursing students along with faculty advisors.

\section{Sample and Recruitment}

Prior to sampling, the research team immersed themselves in conducting a literature review to enrich current understanding on the topic. The target study population included current and recently graduated BSN-to-PhD students studying at various programs in diverse geographic regions throughout the United States. Study participants were selected via convenience sampling. Inclusion criteria required that students were currently enrolled or recently ( $<5$ years) graduated 
from an accredited BSN-to-PhD program within the United States and between the ages 21 to 65 years. Students of all genders, ethnicities, and backgrounds were invited to participate in the study; no student who fit the inclusion criteria was excluded.

Doctoral program directors from geographically diverse universities were contacted via email and asked to forward the invitation to current and recently graduated BSN-to-PhD students asking them to voluntarily participate in the study. These program directors were provided an Institutional Review Board (IRB) approved recruiting email for the students as well as a copy of the questions that would be asked in the online questionnaire. Using the link provided in the recruiting email, participants were able to access the survey online, provide consent, and then submit their responses.

\section{Data Collection and Analysis}

Approval by the XXX IRB (\#2013029800) was obtained prior to conducting this study. Participants responded to open and closed-ended survey questions via an IRB-approved online survey platform. The questionnaire, developed by the researchers, was distributed to the participants and completed via an email link following the informed consenting process at the beginning of the survey. Data were collected between August and December 2013. No compensation was provided for participation. All information was kept confidential with considerations of ethical concerns. Demographic and doctoral study questions as attempted to highlight areas that were believed to be relevant to student life.

Statistical analyses of demographic data were performed using SPSS 22.0 (IBM Corp., Chicago, IL). Textual data were analyzed by data immersion and line-by-line analysis and data reduction by multiple researchers (Cohen et al., 2000). Data were subjected to line-by-line coding without losing sight of the meaning of the whole encounter (Cohen et al., 2000). 
Tentative categories were named and grouped together to form tentative themes (Cohen et al., 2000). Researchers initially followed this procedure independently, then compared categories and themes. Then, the identified categories and themes were reviewed by the research team and final themes evolved and agreed by all members in the analysis team. All members of the research team brought different perspectives, thereby reducing bias and ensuring trustworthiness (Cohen et al., 2000). Furthermore, data analysis team maintained journal notes to record reflections on an ongoing bias and kept the study design open for members of the research team (Cohen et al., 2000; Keim-Malpass et al., 2013).

\section{Results}

A total of 21 participants enrolled in the study, representing seven different BSN-to-PhD programs. Basic participant demographics are shown in Table 1. Notably, all participants were female with four ethnicities represented. Participants were relatively young, with the majority (66.7\%) under 40 years of age. Estimated, average time to program completion using the participant-provided start year and projected graduation was 5.7 years. A total of four (19.0\%) participants from two (9.5\%) universities noted that their programs award Master of Science in Nursing (MSN) degrees along the way to completing the PhD program. One (4.8\%) participant also completed an MSN degree but this was due to being enrolled in both the MSN and BSN-toPhD programs simultaneously.

Qualitative data analysis highlighted aspects of the programs that were successful and areas for improvement, from the participants' perspective. Experiences of participants fell into the major themes of opportunities, challenges, and recommendations for programs and students. Within opportunities, the sub-themes of personal development, contribution to the profession, and time to completion were identified. Academic challenges, social isolation, and financial 
support were challenging areas that participants referenced. The theme of recommendations for programs and students had sub-themes of general preparation for students, better academic support and program structure, and orientation and mentorship. Recommendations from study participants for preparing to be in a BSN-to-PhD program are shown in Table 2.

\section{Opportunities}

Personal Development. Study participants frequently described additional opportunities made available to them as reasons for initially pursuing a BSN-to-PhD program. Among these were personal development in the form of growth and achievement. One participant stated that she chose to enter a BSN-to-PhD program “to obtain the highest degree possible.” Another stated that getting a PhD "meant my career was full of options." Others described being able to obtain a terminal degree earlier on in her career as important and as such thought it best to put plans in place to obtain this terminal degree at once. One participant regarded the decision to pursue a BSN-to-PhD as a "natural progression” in her career. For most the desire to pursue the program rose from an aspiration to teach and conduct research. A minority of participants had goals to continue clinical practice, enter industry, or administration. One participant expressed "I wanted to be perceived as a credible representative (i.e. nurse scientist) to offer guidance on issues impacting our aging society.”

Contribution to the Profession. There was a strong sense of the need for participants to help to advance the nursing profession while achieving personal goals. Many identified their individual career development ambitions to be aligned with goals of moving the profession of nursing forward. Most participants planned to contribute to the nursing discipline by pursuing research and teaching upon graduation. Many expressed the desire to "build upon the profession with new evidence" or to "become a research scientist and contribute to scientific development in my area 
for other nurses and nurse researchers" or that "research could help improve care of the aging population.” Although each participant had plans to contribute to the nursing profession, some planned to contribute to the nursing profession by staying in their respective clinical area. Yet still, other participants described desires to advance the profession in other ways: "I made the final decision [to do the BSN-to-PhD] to allow me opportunities to impact health policy specific to the long term care industry. It was important for me to build upon the profession with new evidence.”

Time to completion. The fast-paced and timesaving nature of the BSN-to-PhD program was a major attraction for study participants. Described by a participant as the "most expeditious route", the time saving attributes of pursuing a BSN-to- $\mathrm{PhD}$ program cannot be overstated. The influence of a comprehensive yet compact program, was often linked to personal as well as career advancement goals. "I understood the importance of getting an early start on my research career and what that would mean for my future.... I also saw the value in finishing my education prior to starting a family." Similarly, another participant expressed "I liked expediting the process of getting the degree [and] being able to focus on my scholarship goals.” Participants in MSN-awarding programs were just as adamant about the benefit of a fast-paced, all-inclusive route as those in programs that did not award a master's degree. "I was 32 when I applied and thought that regardless of what I did with a master's degree, by the time I was 55 [years old] I would need the $\mathrm{PhD}$ anyway, so it was better to just bite the bullet and do the whole thing!”

\section{Challenges}

Academic Challenges. The most serious of perceived challenges expressed by participants was related to academics. A few issues related to the internal curriculum were identified. One participant stated, “I thought the BSN-to-PHD program would save me 20 hrs, but it didn't 
because more classes were added on by faculty after the program of study was completed.” Twenty hours translates into $1.5-2$ semesters of coursework. Interestingly, perception of the length of the academic programs varied widely, as there was no standardized length for BSN-toPhD curricula across a particular school. Several participants mentioned that their coursework felt too long, such as this example: "First year of program spent taking two DNP [Doctor of Nursing Practice] classes that provided no useful foundation for PhD studies...courses that really don't add anything to the program [should be eliminated].” In the United States, the DNP is a practice-based doctorate and focused more on application of evidenced based nursing research. The PhD program prepares future nursing scholars to create original nursing research. In addition, a lack of some courses, such as formal instruction for grant writing, or poorly managed courses were mentioned. Moreover, since the curriculum is quite long, one participant took the statistics course at the beginning of the program, but it was hard to recall this critical knowledge at the dissertation stage.

The academic challenge of issues related to internal curriculum was compounded because of the perceived lack of proper guidance. Specifically, the relationship with faculty, including limited communication between students in preparation for the program, was identified as a key factor. One participant mentioned that "communication between students and faculty is poor, and the school does not foster regular meetings. It is, at present, a go-it-alone type program.” Another participant with similar feelings believed this poor communication was related to the lack of faculty preparation for guiding BSN-to-PhD students. A lack of structural guidance from the school, such as orientation and regular meetings were revealed as perceived barriers by many participants, while others noted that "the faculty is engaging, supportive, and kind. Another stated that "there is a very nurturing atmosphere". These positive feelings of connection with 
faculty were a minority of the opinions expressed by participants. Lastly, one participant noted in particular that awarding a MSN degree during the BSN-to-PhD program would be beneficial as students “can complete all coursework and end up with nothing (no master’s award is allowed) if [you] do not pass [the] Comprehensive Exam.”

Social Isolation. Social isolation was a common theme viewed as another challenge that BSNto-PhD students reported. Several participants noted that they desired and believed a cohesive cohort was important to the structure of the program. The unique characteristics of the BSN-toPhD program, which has few students in each yearly cohort, perhaps caused detachment from peers for some participants. "I am one of 3 students, and we are all in different cohorts. More experienced students and those with master's degrees [are] very judgmental of the [BSN-to-PhD] program and students. [This is] very isolating from a social perspective.” This was also perceived to influence participant academic performance to some degree as well. Another contributor to social isolation was a lack of regular meetings or student events and poorly managed meetings. "Not anything [was done] specifically for the BSN-to-PhD students, but we made an effort to stick together. It is a really long program. It would be helpful for us to have some regular meetings along the way.” One participant mentioned that there was an attempted to put together a mentorship meeting with the director of the PhD program and new BSN-to-PhD students. However, it was not found to be helpful and "everyone eventually stopped going. And the faculty member stopped scheduling [it].” A participant succinctly stated “orientations [are] not helpful; no continued sense of camaraderie throughout the semester. The participant went further to state that "students [are] very isolated."

Financial Support. Limited financial support was the third main perceived challenge of the BSN-to-PhD students. Almost every participant identified financial support as a crucial 
characteristic for finishing the program successfully and timely. The financial support systems in place at represented schools varied from no financial support to a comprehensive, reliable system. Most participants reported that financial aid was available to some degree, but was overall not conducive for completing the program as desired. "Financially, I received only graduate student instructorships and loans. Due to the high cost of the program, I had to take several GSI [Graduate Student Instructor] positions and any other work I could get...this severely crippled my progress in my program.” Another reported similar circumstances: “We are informed of potential scholarship and grant opportunities and there are student aide positions available (If you are willing to work for almost nothing and your tuition paid).” Poorly managed financial support systems, including limited scholarships, was mentioned as one of the main challenges that many participants experienced. One participant explained the disbursement of financial support as being poorly managed, often arriving late due to inadequate disbursement processes.

\section{Recommendations for Programs and Students}

General preparation for students. Study participants frequently mentioned the importance of students needing to be prepared for and learning requirement details of BSN-to-PhD programs in advance. "I felt more prepared than some of my other peers because I had clear expectations going in. I am not sure my cohort fully understood what they were getting into.” Addressing the challenges noted in these programs, many participants recommended prospective students prepare for the academic, social, and financial demands of entering such a comprehensive and lengthy program. "Know that is it an ultra-marathon and not a quick program. Be sure it is what you really want." Similarly, another participant recommended to "have a fairly solid idea about your research idea before starting the program, that way any coursework can be on that topic and 
gets that much closer to dissertation completion and graduation!” For programs that award an MSN during the process, participants recommended completing the master's courses first, then moving on to doctoral-level work. This was seen as a good way to prepare for PhD courses and to better focus one’s research questions.

Better program structure. Participants stressed the need for improved program structure. Regarding coursework, students believed that non-essential courses should be removed. One participant suggested adding a course or addressing additional topics in multiple courses throughout the program: "I would like to see more courses that provide empowerment and leadership...this is so important to ensure those with PhD's work at their fullest potential after graduation.” In addition, not receiving a MSN along the way was raised as frustrating for many of the participants; awarding a master's degree was recommended by several participants. One participant also addressed the idea of taking courses in another doctoral program, however she felt this did not add to the PhD foundation. Lastly, students noted that they wanted the program to be kept as short and fluid as possible, otherwise, "it is so long that it is hard to keep momentum or excitement regarding the work.” This was also confirmed with students noting timing or order of courses in the program was not always perceived as optimal.

Orientation and Mentorship. Participants favored programs with a formal orientation program as well as strong mentor relationships. Suggestions were made for "structured orientation/mentorship” such as “immersion days at the start of each semester” and "yearly performance evaluation and regular meetings with academic faculty advisor.” While most programs offered some type of orientation, most participants believed these were not adequate and preferred some sort of on-going events throughout the academic year. Another student recommended "mixers for new students and faculty, assigned to co-hort for academic and 
personal support, open communication with a faculty advisor.” Not only was mentorship with faculty important, but participants yearned for mentorship from experienced students further along in the program. Participants sought “enhanced peer-to-peer support”, “meet and greet of other nursing PhD students", and to be "paired with a partner student in the program for moral support.” These peer-to-peer mentorships were important social and academic resources, as one participant noted, "I have grown to respect and value my classmates for helping me to get through it and for encouraging me not to quit.” Another student expressed "I enjoy being intermingled with those in various stages in the program. This is a good learning experience.”

\section{Discussion}

This study provides critical understanding of BSN-to-PhD students and education by exploring the perceptions and experiences of current and former students of BSN-to-PhD programs throughout the United States. These results reinforce that BSN-to-PhD students' motivation to choose their education route is both for personal growth and development as well as contribution to developing the nursing profession via the pursuit of diverse roles in academia or integrated practice roles. This is consistent with findings from the PhD program directors' observations that they are over-achievers with a high level of motivation (Ellenbecker \& Kazmi, 2014). In addition, BSN-to-PhD education is uniquely chosen for practical reasons, such as the relatively short time to complete the program, as well as the more flexible schedules that the program allows, compared to the traditional master's and PhD program. This flexibility allows for students to save time and balance their practice and academia, and their personal life better. In the United States, a master’s degree in nursing generally takes 1-2.5 years of full-time study and a PhD typically requires 3-6 years beyond the master's-level education. Results of this study estimating time to degree of 5.7 years for the BSN-to-PhD program is comparable, if not slightly 
faster, than completing a master's and PhD separately. When factoring that most students will work at the master's level before returning to complete a $\mathrm{PhD}$, the time of doctoral-level contribution to the discipline is at least several years more by taking the BSN-to-PhD route. Many students complete both their master's and $\mathrm{PhD}$ with only small changes to both curricula to create the joint degree; however, the seamless transition as well as networking and discussion of research during the master's coursework can accelerate the $\mathrm{PhD}$ completion. These benefits could be useful for recruiting more students in PhD programs, as commitment for a long period of time in academia presents major challenges for $\mathrm{PhD}$ students.

Insights of participants of this relatively new education program may be helpful in overcoming some of the challenges associated with BSN-to-PhD programs. More tailored academic preparation for the $\mathrm{BSN}$-to-PhD program is needed due to the unique features of the program, such as heavy academic load due to the relatively short time frame. In addition, stable financial support is emphasized, which is consistent with the previous studies (Ellenbecker \& Kazmi, 2014; Nehls \& Rice, 2014). This is potentially because BSN-to-PhD students are sensitive to finding feasible ways to sustain their studies. In addition, social support needs to be addressed, not only for them being in such unique situations, but also because it is a major contributing factor for students to be successful in completing their studies (Ellenbecker \& Kazmi, 2014). Beck’s (2001) metasynthesis indicates that creating a caring environment between faculty and students enhances the mentoring relationship and the work done by both groups. Beck describes the beneficial effect begins with positive, within-faculty camaraderie which translates into better faculty-student relationships and then into enhanced student-student caring for each other. 
In spite of the many values of this study, there are some limitations. Because of a small number of participants, it might not be appropriate to generalize findings. Additionally, responses for online surveys often garner the support of those who are quite pleased as well as those who are very frustrated. Alternatively, researchers may need to further explore these experiences with face-to-face interviews. This method may allow for a larger number of representative participants.

Research bias can occur in the planning, data collection, analysis and/or publication phases (Pannucci \& Wilkins, 2010) and some limitations are beyond the control of the researchers (Milne \& Oberle, 2005). The predispositions, perceptions, and biases of the researchers may affect data interpretation (Patton, 2002). This limitation may be evident in this study as all of the researchers are either current students or graduates from the same BSN-to-PhD program. Even though the researchers have diverse backgrounds-all members of the research team have different BSN educations with four of its members being educated outside the United States - the homogeneous experience of the researchers in the same BSN-to-PhD program may bias perceptions of other programs. Given the fact that individuals have a tendency to compare or relate to experiences that are similar and familiar to them, this could have biased the themes chosen from the content analyses.

\section{Recommendations}

Based on findings from this study, including participant feedback as shown in Table 2, several areas for supporting BSN-to-PhD students are recommended, given that they are a special group who request additional support, mentorship, and resources. Annual PhD orientations could occur prior to the start of each new academic year. If the event was collaboratively planned by both students and faculty this may enhance its effectiveness and 
reception by the students. Orientation could be organized to help both new and returning students to learn about university and school resources, program structure, other information relevant to respective phases of the program, and a time to meet and network with faculty and other students. An organized and active student organization can support students through special programming and events each semester, as well as pairing seasoned students with newcomers. In addition, these students could engage in a peer mentoring group involving all BSN-to-PhD students in the program. Students could meet at monthly intervals, with more experienced students mentoring newly matriculated students.

Many BSN-to-PhD students expressed the desire to be awarded a MSN degree during their studies. Selection of and achieving an appropriate MSN degree provides both an uplifting milestone and a way to enhance the future program of research. Additionally, students should identify a program of study with the help of the academic advisor during the first year so that the coursework expectations are transparent, course assignments can be tailored towards the area of interest, and the anticipated graduation goal has a fixed date. Students should feel free to change academic advisors to one who can meet both research interests and mentorship needs.

As financial aid appears to be a major area of concern, this area should be highly transparent and structured. As part of the academic planning process, financial aid should enter the conversation and be mapped out just like the coursework plan for graduation. Opportunities to work as a teaching or research assistant may be one avenue to help defray costs of attending the program. BSN-to-PhD students would benefit from taking grant writing courses and should submit a proposal prior to graduation. This could be an additional source of funding for many students while simultaneously preparing them for grant writing in the future. Fostering interdisciplinary collaboration between and within other schools around the university will 
strengthen research and may offer a wider variety of grants and other aid. Although it may require extra effort matriculating BSN-to-PhD students each year, schools should provide a strong commitment to support, encourage, and mentor these students.

\section{Conclusion}

This study is one of the first of its kind in exploring BSN-to-PhD programs, focusing on the perceptions of current or recently graduated students from such a program. These data highlight aspects of the programs that are and are not successful from the students' perspective and can help current nursing educators revise these programs to be more attractive and successful for current and future students. In addition, this study may contribute in helping national nursing educators develop standard educational criteria for BSN-to-PhD education with evidence-based principles, as well as develop an innovative conceptual model for successful $\mathrm{PhD}$ education.

Additional work is needed to further examine BSN-to-PhD education programs from different perspectives. For example, perceptions of administrators or nursing educators' need to be explored to provide perception of gaps between students and faculty perceptions and to seek novel approaches to improve BSN-to-PhD programs. This may be done best by examining the characteristics of existing programs and the experiences of enrollees by a heterogeneous group of researchers from various institutions, including a mix of students, faculty and administrators. This may reveal current program successes and pitfalls with a goal of improving the experiences of current and future enrollees, thus attracting qualified nurse applicants to such programs earlier in the career trajectory. In addition, there may be merit in following the careers of BSN-to-PhD students long-term, as well as academic achievements, while comparing them to those of traditional PhD students to help obtain more in-depth understanding and potential support for such programs. 


\section{References}

American Association of Colleges of Nursing (2013a). Institutions offering doctoral programs in nursing and degrees. Retrieved from http://www.aacn.nche.edu/research-data/DOC.pdf

American Association of Colleges of Nursing (2013b). Schools offering baccalaureate to research-focused doctoral programs, fall 2013. Retrieved from http://www.aacn.nche.edu/research-data/BACDOC.pdf

American Association of Colleges of Nursing (2014). Faculty shortage factsheet. Retrieved from http://www.aacn.nche.edu/media-relations/FacultyShortageFS.pdf

Beck, C. T. (2001). Caring within nursing education: A metasynthesis. Journal of Nursing Education, 40(3), 101-109.

Berlin, L. E., \& Sechrist, K. R. (2002). The shortage of doctorally prepared nursing faculty: A dire situation. Nursing Outlook, 50(2), 50-56. doi:http://dx.doi.org/10.1067/mno.2002.124270

Cathro, H. (2011). Pursuing graduate studies in nursing education: Driving and restraining forces. Online Journal of Issues in Nursing, 16(3).

Cohen, M. Z., Kahn, D. L., \& Steeves, R. H. (2000). Hermeneutic phenomenological research: A practical guide for nurse researchers (Vol. 2). Thousand Oaks, CA: Sage Publications.

Ellenbecker, C. H., \& Kazmi, M. (2014). BS-PhD programs in nursing: Where are we now? Nursing Education Perspectives, 35(4), 230-237.

Keim-Malpass, J., Albrecht, T. A., Steeves, R. H., \& Danhauer, S. C. (2013). Young women’s experiences with complementary therapies during cancer described through illness blogs. Western Journal of Nursing Research, 35(10), 1309 - 1324. 
McBride, A. B. (1999). Breakthroughs in nursing education: Looking back, looking forward. Nursing Outlook, 47(3), 114-119.

Milne, J., \& Oberle, K. (2005). Enhancing rigor in qualitative description: A case study. Journal of Wound, Ostomy, \& Continence Nursing, 32(6), 413-420. Retrieved from http://ovidsp.ovid.com/ovidweb.cgi?T=JS\&CSC=Y\&NEWS=N\&PAGE=fulltext\&D=me $\mathrm{d} 5 \& \mathrm{AN}=16301909$

Nehls, N., \& Rice, E. (2014). Early entry to a doctoral degree in nursing program: Analysis of student experiences. Journal of Nursing Education, 53(4), 223-228. doi:10.3928/01484834-20140327-01

Pannucci, C. J., \& Wilkins, E. G. (2010). Identifying and avoiding bias in research. Plastic \& Reconstructive Surgery, 126(2), 619-625. doi:10.1097/PRS.0b013e3181de24bc

Patton, M. Q. (2002). Qualitative research and evaluation methods (3rd ed.). Thousand Oaks, CA: Sage Publications.

Scherzer, T., Stotts, N. A., \& Fontaine, D. (2010). Meeting the nursing faculty shortage challenge: An accelerated doctoral program in nursing. Journal of Professional Nursing, 26, 366-370. 